\title{
Coping Strategies for Youth Suffering from Online Interpersonal Rejection
}

\author{
Aviv Y. Landau \\ University of Haifa \\ aviv.landau@gmail.com
}

\author{
Zvi Eisikovits \\ University of Haifa \\ zvi@soc.haifa.ac.il
}

\author{
Sheizaf Rafaeli \\ University of Haifa \\ sheizaf@rafaeli.net
}

\begin{abstract}
The Internet and social media have rapidly changed our lives, and are profoundly affecting the social lives of adolescents, expanding and enriching their communication options. At the same time, they often operate as a platform that amplifies the real-world phenomenon of interpersonal rejection - a harsh and excruciating experience. In this study, we will examine, youth's coping methods with online social rejection from a psycho-social perspective. To achieve this objective, a data-based heuristic model was developed, based on indepth interviews with 19 adolescents from Israel who experienced online rejection. The findings show several coping strategies ranging from adaptive to maladaptive online and offline used interchangeably.
\end{abstract}

\section{Introduction}

The need to belong is a central human experience that reflects the great importance of our social behavior and explains the motivation to avoid interpersonal rejection [3]. Accordingly, interpersonal rejection is a painful experience [30], which can lead to a variety of coping methods $[38,44]$.

While belonging and rejection have always been relevant, society is changing, and technology is rapidly developing new ways by which they can connect and experience our world as a "smaller one" [34]. The Internet revolution created an unprecedented opportunity to link people with existing social ties, as well as expanding to new social relationships [37]. Moreover, the unique features of the Internet provide people with a psychological environment that can be distinguished from the offline world [27]. However, despite the significant progress in helping people connect through online networks, the potential of interpersonal rejection continues to remain a real social threat online as well [42].

The interactions of people using online social networks such as Facebook, YouTube, and LinkedIn are a current focus of significant research interest both the social and psychological levels. In the present study, we will consider various approaches to interpersonal and peer rejection, based on the assumption that there is a broad range of different kinds of social interactions in social media [42].

The contribution of this research lies in that, to the best of our knowledge, it will be the first to use the descriptive phenomenological method in investigating interpersonal rejection among youth in online social networks from youth's subjective view, The primary objective of the present study is to understand through an insider's perspective how youth cope with online rejection in order to construct a heuristic model based on data gathered through qualitative research .This can shed new insights and expand the knowledge-base on understanding and intervening with this phenomenon.

\section{Background}

\subsection{Interpersonal Rejection}

Interpersonal rejection entails ostracism, social exclusion, and rejection [38]. Rejection occurs at times when one perceives that he is not liked in a given social setting [18].

The experience is hard to bear, and even when individuals are not rejected outright, the very idea stimulates frustration and sadness [20]. Four fundamental needs are threatened when rejection is at its most extreme point of complete ostracism and exclusion: (1) Sense of belonging - the excluded and ostracized individual is disconnected from his peers, and they stop attending to his desires and needs; (2) Sense of control is harmed because rejecters do not negotiate the terms and reasons of being a candidate for rejection; (3) Self-esteem is compromised because most processes of rejection are executed without explanation: as a result of an attempt to understand the purpose of the rejection, the rejected individual will eventually blame himself; and (4) Meaningful existence is at risk because of the 
pain, hurt and sense of death that arise from being rejected [43].

Children and adolescents have a unique and distinct reaction to rejection compared to adults. Youths who are experiencing rejection are known to manifest high risk of maladjustment. Socially rejected youth disengage and marginalize themselves from school activities, eventually expanding their lack of social interaction [8] and feelings of loneliness [1]. Furthermore, peer rejected children are more likely to drop out of the educational system [29], be involved in delinquency [28], and act out by extreme manifestations of suicidal and life-threatening behaviors [15].

It should be noted that not all coping methods and their consequences involve adverse outcomes [19]. Studies have showed that individuals who experience rejection aim to increase their sense of belonging within society using prosocial behavior [13] manifested through social conformity, devoting time and effort to work and attempting to behave in a more sensitive manner towards their peers [45]. Furthermore, excluded and marginalized individuals who seek to eliminate their stigmatized condition and improve their relations with others may attempt specific behaviors such as obtaining higher education, going to therapy, and connecting with similar others with whom they feel a sense of togetherness [25].

\subsection{Youth Online}

The role of the Internet in the lives of its users is daily and breathtaking, especially for the young generation born to a new reality [6]. The Internet allows youth to obtain an education, socially interact, selfexpress, be creative, participate in civic engagement, and take part in online activities [22, 23]. Furthermore, it allows youth to find valuable information that can assist in their search for exploring their identity [10].

Besides its opportunities, the Internet and online social networks involves many risky, negative and disturbing features [40] and the more people use the Internet and encounter its opportunities the more they may be in danger. Therefore, youth who are more aware of the advantages of the Internet and its opportunities are more likely to be at some risk [6]. Youth can be exposed to exclusion [36], ostracism [44], cyberbullying, harassment, pedophiles, racism and much more damaging content [23]. As a result of the potential online risks understanding the psychological context, detecting [41] and intervening [24] have significant social value.

In the present research the authors define online interpersonal rejection as a subjective experience due to active or passive forms of online behaviors and expressions such as unfriending, cyberbullying, and excluding from groups. Such acts are interpreted as rejection by the interviewees. In other words, cyberbullying and exclusion from groups are the acts while rejection is the interpretive conclusion of such acts.

\section{Method}

This research is designed to address to a conspicuous lacuna, and will seek to examine different coping strategies of youth who have experienced interpersonal rejection in online social networks, with regard to their conscious perceptions of the ongoing experience as recounted in the present [14]. This study uses the descriptive phenomenological method in order to construct a heuristic model based on data gathered through qualitative interviews, on the experience of online interpersonal rejection through the eyes of the interviewees [11]. For the researchers to implement a descriptive phenomenological approach they must assume an appropriate attitude, resisting the handling of the given information with a preconceived theory in mind. By bracketing his/her own preconceived theoretical or ideological position the researcher enables the informant's perspective to shine through [14].

\subsection{Sample}

Nineteen Israelis between the ages of 13-18 from different social and cultural backgrounds [16] such as, Jews, Arabs, immigrants and LGBT's that reported active or/and passive forms of online rejection were interviewed. The interviewees for the current research were recruited by social workers and school counselors. The interviews lasted about an hour and a half each. To achieve sufficient coverage of the phenomenon, the sample size was determined by theoretical saturation or obtaining redundancy in the emerging themes from the interview transcripts [32].

The interviews were guided by a semi-structured interview guide. This format, enables the interviewees to tell their authentic story in the context of their subjective beliefs, perceptions, feelings and worldviews [17] yet ensures that certain topics considered indispensable for the researcher will also be addressed. According to a descriptive phenomenological method, the interviewees were directed to describe rather than interpret their experiences. [11, 14].

\subsection{Data analysis}

Although qualitative data is based on soliciting systematic description and subsequent analysis, creativity and critical thinking are essential for the 
qualitative researcher [39]. A cross-case approach guided the analysis of the qualitative data collected in constructing a conceptual framework. Central issues from each interview were grouped into themes and categories [7]. The data collected enabled to construct a databased heuristic model conceptualizing the online coping methods of the socially rejected individual [2].

Maxwell, [26] argues that the researcher must choose his strategies wisely and not by default for acquiring trustworthiness. In this current research, credibility was accomplished through a number of strategies: Referential adequacy, prolonged engagement, member checking, peer debriefing [21], and rich data [26].

\subsection{Ethics}

The interviewees in the current research are youth under the age of 18, and therefore, informed consent of the children and their parents was necessary for their participation. Furthermore, it was important to present the aim of this study, both in writing and verbally, including the right to refuse to participate or to end the interview. During the interview, the researcher was sensitive and alert to the interviewee's state of mind. At the end of the interview, the interviewees were given a list of emergency phone numbers in case of an outbreak of severe emotions. In addition, confidentially is fundamental, and the researcher did everything in his power to protect the interviewees anonymity.

\section{Findings}

The descriptions below will illustrate the different strategies rejected youth use in order to cope with online interpersonal rejection. It is important to note that several of the youth interviewed suffered simultaneously from both online and offline forms of rejection and therefore, consider the process as a unified experience. A summary of the subthemes and categories names are presented in Table 1 below:

Table 1: A list of the subthemes and categories

\begin{tabular}{|c|c|}
\hline $\begin{array}{l}\text { 4.1 Adaptive } \\
\text { coping: }\end{array}$ & $\begin{array}{l}\text { 4.1.1 Obtaining help online and } \\
\text { offline } \\
\text { 4.1.2 Not being alone } \\
\text { 4.1.3 Regaining a sense of } \\
\text { belonging offline and online }\end{array}$ \\
\hline 4.2 Withdrawal: & $\begin{array}{l}\text { 4.2.1 Moving to a different } \\
\text { school and other online social } \\
\text { networks } \\
\text { 4.2.2 Eliminating the online } \\
\text { memory of rejection }\end{array}$ \\
\hline
\end{tabular}

\begin{tabular}{|l|l|}
\hline & 4.2.3 Totally disconnecting \\
\hline 4.3 Maladaptive & 4.3.1 Taking it to the extreme \\
coping: & 4.3.2 Using force \\
& 4.3.3 Self destruction \\
\hline
\end{tabular}

\subsection{Adaptive coping methods}

The subtheme below will present a broad range of online and offline adaptive behaviors manifested by youth coping with rejection.

4.1.1 Obtaining help: The account below shows how professional treatment helped Chen (18) cope with interpersonal rejection.

Chen: For real, my school constantly tried to refer me to a counselor, psychologist, therapist, coach. After a couple of times I got hurt from these kinds of people because every time I told them what bothered me, they went to my parents and I felt as if I was stabbed in the back [...] I developed a sort of antagonism [...]. In my new school, they introduced me to a wonderful psychologist that I connected to, and he did not pity me, and did not look at me as if I was miserable but argued with me and made me reach many conclusions about myself.

Throughout her description, Chen spoke about her initial lack of trust in therapists. However, she was able to sidetrack her prejudices and devote herself to the treatment process. The ability of her therapist to facilitate, contain, be discrete, and not feel sorry enabled her to develop a beneficial professional relationship. Her willingness to share her problems helped her cope and feel secure, preventing the rejection experience from becoming exacerbated.

The next quote illustrates how online social networks offer ways of getting help. Marina (16) a second-generation immigrant felt that she has become a source of ridicule and bullying describes how she convinced the supervisor in charge of a Facebook group that she participated in, to erase her photo.

I asked the group supervisor twice to delete the picture, but he didn't delete the photo, he didn't.

Then, the third time I wrote him a scroll so he can delete it and that like I am so exhausted from it all, and then he said ok I'll delete it.

Unlike Chen, Marina insisted on getting help, and her stubbornness paid off. Her ability to share her feelings with the group supervisor made him change his mind and delete her nude picture, suggesting that help is available at the very platform that was the source of the problem.

4.1.2 Not being alone: The quotes below will describe how rejected youth got guidance from their siblings and 
used social media for advice and support, and a platform to share their story.

Kobi (17) describes how he shared his difficult experiences with his parents, and how they tried involving the authorities.

After a while, I went to my parents, and they contacted almost the whole world. [...] My mom [...] is like a lion [...] she attacks, and besides, she is a police officer, and it helps under these kinds of circumstances. She tried, my parents battled hard, but it didn't help anything [...] They started with the principal [...] it only made me a rat. They went to the Ministry of Education, and they said [...] we will take care of it; they didn't.

Kobi talks about his mother with great admiration. His ability to feel and understand that his parents and especially his mother supported him was essential to his sense of safety and belonging. Despite the unfortunate outcome - his friends treating him as a snitch - his parents' battle for his wellbeing left a great impression on him. The inability of the education system to provide him a safe environment is similar to the experiences of other interviewees, who felt rejected both by their peers and by their school.

The next two quotes describe the effectiveness of using online social networks to share experience and feelings.

Vered: I used to write all my problems there, and what's good is that no one knows who I am. They cannot judge me, what's good in this place is that nobody is judged; it doesn't matter if you're ugly, fat [...] If someone gets judged there, then we report him, and everybody hates him. [...] if he judges you, then the other kids will reject him. There, everybody is connected, there we can meet. Even if we don't meet, then we talk.

Vered speaks about a parallel online community on Facebook where members can communicate and share their feeling anonymously. All have pretended names and profile pictures. In this unique online community, there are strict rules about how to behave and communicate. One's appearance is irrelevant, and no one is allowed to criticize or write nasty remarks. Ironically, if anyone violates the norms and rules of the group, they are excommunicated. For Vered, the possibility of interacting and sharing her life online helped her cope with the lack of friends in school, to be her true self, feel normal and protected. The added advantage of protection against a negative response gives rejected teens hope and enhances their selfconfidence.

Unlike Vered, Moran (18) shared her thoughts and feelings online with people she met daily.

It was a sort of relief. Finally, I shared and told my story because everybody or most of them didn't know
[...]. They asked me why am I not going to school, and all the time there were rumors [...] but no one understood how serious it was. [...] So, I felt and told myself that if they see it then maybe they will understand that what they're doing is not right. Until today I left it there and did not delete it. [...]

The account above is an example of how online social networks can act as a platform for youth to express themselves. Moran felt a sense of relief when she decided to share her experience and explain what happened to her, and how much she suffered. Afterward, she decided not to delete her post, thus transforming it into an online monument. Her ability to share and not be ashamed of her past helps her cope and open a new page in life.

4.1.3 Regaining a sense of belonging offline and online: The category will enrich our knowledge about the various strategies and opportunities rejected youth use in both the physical and virtual worlds to regain the sense of belonging.

Marina (16) explains how she started to go out and how a good friend helped her regain her confidence.

After two months, I like started going out [...]. A friend of mine gave me the confidence to tell everybody that it wasn't me and that I have to stand up high, and that everyone who knows me understands that it wasn't me.

Marina talks about how a close friend convinced her to confront her friends so that they will believe her story. During her interview, she recalls how he supported her and stood by her throughout her rejection. Not being alone helped her find the courage to go out again and fight back the rumors and false accusations. The importance of feeling belonged and supported is fundamental for Marina in regaining her confidence, allowing her to stand up to their rejecters.

The next quotes illustrate how youth regain a sense of belonging with the help of social media. Amit (15) who at the time was also unsure about his sexuality was rejected simultaneously both online and offline by his peers in school speaks about how he virtually meets his online friends during the night, and how he feels afterward.

Fun, not being alone, and being surrounded by people you love and who love you. [...] It's fun after being alone for a while, and staying home because you don't want to be with that sickening feeling. So, you prefer staying up all night and then when they come to wake you, you go to sleep.

After experiencing rejection, social media enabled Amit to meet new people, have fun and feel normal. His feeling of loneliness was reduced, and he felt that communicating online enabled him to put aside his "sickening" feeling. The night became time for social 
activity while daytime was for sleep and withdrawal. Amit felt so attached to his new friends that he used the word "love" to describe their connection. Furthermore, in this interview, he explained how he joined a Facebook group who worshiped a famous singer, and how that group would also meet in public places. Despite being rejected online as well, Amit was capable of taking advantage of the benefits social media had to offer.

Anna (18) who was born in Russia describes how she felt satisfied when followed and when she supported others in social media.

When you have people supporting you, it makes you forget all the hating. Let's just say that it will be enough if ten people will help me and another twenty will say no to hating. Because when people truly support you and actually come to see you, and if I upload a photo at $4 \mathrm{am}$, and they write: "I' $m$ the first one to see it and well done”, it makes you feel really good. When a person tries to make you look bad or curse you, and you don't have to respond because other people confront him and say that you don't even know her [...] you feel pleased with yourself.

She explains how online support of others helped her deal with the "hating". Anna's followers on YouTube defended her and made her feel encouraged. The fact that she was not alone when rejection occurred contributed to her sense of belonging.

In conclusion, the need to belong can be achieved in both the physical and virtual worlds through sports, friends, support, obtaining likes, etc. Youth today have a broad range of options to promote their sense of belonging. The Internet and social media enable them to expand and reach a new circle of friends that was not available in the past.

\subsection{Withdrawal}

The subtheme below will illustrate how youth withdraw from and avoid online and offline interactions as a way of coping with rejection.

4.2.1 Moving to a different school and other online social networks: Six out of the 19 participants of this research described how they changed schools after being rejected. The quote below illustrate how moving to a new school can contribute emotionally, and open up social opportunities that were previously denied.

There I had problems with the teachers and all sort of things, but I chose; no, I didn't choose, just I didn't connect to anyone there; [...]. I didn't have anybody to talk with and here, thank God, I always have friends to talk to, and truly I can say that when
I wake up in the morning to go to school, I smile. (Vered, 14)

Vered distinguished between the old and new schools and the change that they felt after moving. She describes how at her old school she felt alone. However, in her new school she acquired several friends, and when she wakes up in the morning, she is happy. For Vered moving to a different school helped her cope and experience belonging.

Flexibility in the online world is no less important: Salem (16) an Arab Israeli, explains how youth can maneuver between online social groups according to their needs and social situation.

I always have where to go, like there is one group [...] a hundred groups that are racist, but there are always ten groups that aren't [...] the groups of my friends and class that I am in touch with, so there is always that.

Salem, who has suffered online social exclusion, describes how it is always possible to use social media to find groups that believe in diversity Salem believes that even though there many ignorant people on social media, there is always the hope to find a normal voice. The understanding that online social networks offer endless social opportunities and that he can use it them find people who have much in common with him contributes greatly to his ability to cope with rejection.

4.2.2 Eliminating the online memory of rejection: The fear and trauma of rejection force some rejected youth remove content from their online social networks and change their online accounts in order to, regain a sense of control.

The next two accounts refer to erasing content from online social media. Olga (14) describes why she deleted a picture of hers from Instagram.

My mom at the time had Instagram, and she saw the comments. One day I posted a picture, and they wrote on it, "whore," "slut" [...] I saw my mom looking at the pictures [...] so I deleted the picture [...] I didn't want her to deal with it.

Interviewer: Did she ask you?

Olga: She asked me about school and like I didn't know what to do and if I should tell her or not. In the end, I decided not to tell her, and I think it was a missed opportunity. [...] but, like, I don't see a way that she would have done something with it. There is nothing to do with things like this.

Although she was not afraid of uploading pictures online, Olga erased a photo because she did not want her mother to see the offensive comments that she received. She was afraid her mom would know the truth about what the kids in school were thinking about her. Olga believes that her mother is incapable of doing anything, and prefers keeping her secret to herself. On the hidden 
level, despite having deleted the picture, the remarks she received cannot be erased from her heart. Wanting to "protect" her mother and her inability to reveal the truth to her family about her rejection prevents her from coping adaptively and feeling safe.

The next quote describes a different strategy suggested by his parents. Amit (15) opens a new Facebook user without the children rejecting him.

They wanted to close my Facebook. I told them I did and opened a new one, they knew about the new one, and they wanted me to open it, but after a while, I returned to the old one. Who do you think wants to get rid of 6000 friends? It's a lot of work.

His family intervenes and recommends him to erase his Facebook account due to online rejection. However, he does not want to disconnect himself permanently from the virtual world. Therefore, Amit decides to close his original Facebook account and open a new account with old pictures and friends he can trust. He explains that he cannot stand the fact that he has to erase his history. Online social networks enable users to open multiple users and accounts, thus allowing him to stay connected. The possibility of transferring his identity to another account helps cope with rejection temporarily. After a while, he returns to his old account as he cannot overcome the temptation of returning to his 6000 friends. The expectation from Amit to erase his online identity is unbearable. Social media is a significant part of his young life. These actions emphasize the contradiction youth face between wanting to open a new page in life and fearing it too.

4.2.3 Totally disconnecting: Some rejected youths distance themselves completely from physical interactions and online social networks. The category will cover the rationale and justifications youth provide for disengaging from any social contact in response to rejection.

[...] sometimes you can deal with it and sometimes you cannot. [...] There were times that I couldn't [...] talk to anybody because I didn't have the strength and I distanced everybody. Like, either way, they kept a distance, but I just like really distanced myself and didn't speak at all. I put on my headphones on full volume, and that's it. (Sivan, 14)

The pain Sivan felt was so intense that it paralyzed her. Her lack of strength to adaptively cope with rejection prevented her from gaining a sense of belonging and stability. Her mental state deteriorated, and she became depressed. Disconnecting from social interactions can afford momentary relief; however, in the long run, it can lead to maladjustment.

In Daniel's (13) case, the disconnection was online, and total, and he rationalized it as follows.
Facebook, I erased it because it became outdated and because I wasn't in touch on Facebook. On Instagram, I didn't post pictures, and there was no one there, so I erased it too.

Daniel rationalizes closing his online account as a result of boredom. Since online social networks can reflect on one's social status, closing them may temporarily ease the pain but can also prevent successful recovery.

Chen (18) presents a more elaborate rationalization. For a time, I absorbed it all, and I also didn't tell anything to my mom. In the end, she saw me cry, so I told her everything, and we decided that I have to close Facebook. That's what I did. I didn't have Facebook for about two and half-three years, from 9 th grade till 11th grade. That time was very good for me, without Facebook, it's like a different world like, I cleaned myself. [...] they are less aware of the existence of those who are not on social media. I erased myself from the primary network, so they are less aware, and I am less interesting, and I am less interested in people. I am disconnected.

Chen describes it as if she cleaned herself from the burden of rejection. She explains that closing her Facebook made her less attractive and aware of her social environment. The online and offline worlds affect one another, and when shutting down one of them, the effect can be the same. The question that arises is whether closing Facebook is ultimately the best way for her and others to cope with rejection.

\subsection{Maladaptive coping}

The subtheme below comprises the interviewees' accounts and descriptions of justifying unconventional reactions to their rejections.

4.3.1 Taking it to the extreme: The next description is of a more common but highly maladaptive response to interpersonal rejection. Adi (14) describes how she found herself hanging out with "drug addicts."

She took me to places that were really bad, where all the drug addicts are and [...] they offered me stuff, but I didn't [...] take anything. I never tried drugs only alcohol, not drugs.

When Adi was rejected, she stopped coming to school and started hanging out with teenagers who were also at risk. Being rejected led her to deviate from social norms and look for new and dangerous adventures and interactions. At the time, she was self-destructive and was involved in several risky experiences. Only after getting help and feeling accepted in her school, did she stop taking risks and meeting her old friends, which had had a negative influence on her. To survive rejection rejected youth can start a process of self-destruction as 
a cry for help: the need for belonging is so powerful that it legitimatizes all actions taken to regain it.

4.3.2 Using force: Some rejected youth justify using physical force as a way of coping with frustration and being a subject of rejection.

They start calling me names. Do you really think that you will bring me down to your level? Try bringing me down, and you won't be able to. In the end, a kid made fun of me and called me after a dog because of my last name. I was like [...] Who do you think you are? I came to him and gave him a beating [...] (Nina, 13)

I had to use force. [...] It felt like what I felt when they rejected me, all the rage that I had went out on him. (Eli, 15)

Often the experience of rejection is so intolerable that the reaction is immediate, extreme and antisocial. Nina comes to the point that she cannot resist the humiliation and must exercise physical revenge. Eli also had an "educational" rationale: he wanted his rejecters to feel the rage he felt. Like Nina, for him there was no question about it, he had to use force to experience emotional release: subsequently restored their sense of pride and felt no remorse.

4.3.3 Self destruction: The quotes will demonstrate the reasons for attempted suicide and the feelings that arise afterwards. Olga (14) described what caused her to attempt suicide.

I didn't deal with it; I didn't know what to do. To cut, I tried \{chuckles\}, and I said to myself if it continues until this and that date, I am going to jump out of a window. I am going to take sleeping pills and that. In the end, I am here in front of you, and I didn't do any of that stuff, and if I had a thought, in the end, I only thought it to myself. Why should they get what they want? Why am I doing this? So, I simply gave up on it and went on with my studies.

At first, she admits that she cut herself, but later on Olga denies it, as if scared from exposing and admitting to herself how fragile she was. The experience of interpersonal rejection was so intense that the only possibility to end it, as she saw it at the time, was death. In her mind, she had no other option, and she was helpless. Eventually, she decided to give up on her plans and continue with her life. It seems that her suicide attempt was a cry for help that unfortunately was not heard. What saved her was the understanding that the result of her death would only strengthen her rejecters and reveal her pain.

The next quote by Amit (15) illustrates his feelings of shame after attempting suicide.

[...] why should I now go around with a scar, and suddenly everybody starts asking you what happened. I have to lie to them, to people I like. So, like it feels a little bit not nice.

The scar on Amit's body remains a warning sign. As a result of hurting himself, he has to lie to his friends and make up stories so he can continue with his life. The thought that he had to physically hurt himself continues to haunt him. It seems that there is genuine remorse and that his actions were a cry for help, as in many attempted suicides during adolescence. The pain of the rejected can be so intense that the only option left to cure it is by playing with death.

\section{Discussion}

Coping with interpersonal rejection is a multifaceted challenge. Consistent with the literature and an insider's perspective, a broad variety of coping methods ranging from adaptive to mal-adaptive and online to offline coexist. Youth seek to redefine themselves during the disruption of adolescence by achieving a sense of hope, independence, and autonomy [5] and may perceive their rejection experience as an advantage that is not worth changing in maturing, experiencing life, and experiencing other difficult situations. To heal the self during interpersonal rejection requires reestablishing meaning and well-being [45], which may be fulfilled in both the online and offline worlds by connecting with significant others, asking for help, sharing, and participating in leisure activities. The Internet through the perspective of the youth interviewed enriches the options youth have when facing rejection, and allows them to move about between online and offline worlds in their efforts to gather themselves back together.

Rejected youth interviewed describe how sharing their experience with family members, friends, therapists, and online contacts has significantly contributed to their feeling a sense of relief and belonging. Online self-disclosure makes it possible for the rejected youth to reach a wider audience, thereby achieving social validation and relief and experiencing a comparable experience to sharing offline [4]. The rejected youth have the option of obtaining online help from group administrators, thus increasing their sense of control, confidence, and belonging. Furthermore, online social networks can act as a social platform for reshaping one's social identity, which can result in meeting new people with similar interests. In a social context, there is more freedom online to present who you may reasonably be or hope to become [12]. For the disconnected, the capability to formulate a parallel peer group can remarkably help in the process of recovery, and these innovative forms of friendships can be constructed through both online and offline interactions, thus providing a normal and healthy social experience. 
Social withdrawal is a common coping method, which ranges from positive to negative impact on the self [38]. Although changing social environments may entail great difficulty and uncertainty, the interviewees' accounts justify their actions and explain how eventually moving to new schools brings about feelings of hope and anticipation to belong. Simply the expectations of having a new beginning without being frightened of the past gives strength and allows rejected youth to be their true selves and feel safe.

Similar to moving to new locales, the virtual world expands the possibilities in which adaptive forms of social withdrawal can be achieved. Although there is a gap in emotional intensity between the offline and online worlds, youth can have endless opportunities to wander between online groups and find a place of belonging. The option to wander around in cyberspace enables an efficient way of continuing life. The understanding of the need for continuity results in a new and unique sense of meaning and restarting of the self [46].

At the opposite end of the continuum of social withdrawal, rejected youth describe how they embrace online and offline solitude and justify their withdrawal. The excruciating experience of rejection causes them to want to run away both virtually and physically by any means. When the self feels threatened it initiates selfprotection to rebuild self-esteem and self-concept [35]. Online networks hold the power to enable reflection upon the experience, and therefore rejected youth attempt to delete their online existence. Moreover, the fear of self-recognition and/or social recognition as deviant threatens the self and causes youth to block others, erase pictures, open new online profiles, and seek solitude.

The interviewees suggested several other forms of maladaptive coping strategies. Interestingly, unlike others, these particular methods were described taking place exclusively on the physical level. The experience of rejection can be so difficult to bear that extremely negative reactions in the physical sphere seem to be the best alternative within reach. The emotionally divided self is described as nonexistent self that becomes a disembodied self divorced from the body, resulting in the need for self-destruction in order to regain feeling and fill in the gaps of the emptied-out inner self [9]. Rejected youth described how they hanged out with adolescents at risk. Furthermore, they fanned the flames of an inner rage, which erupted violently and uncontrollably towards the rejecters and others. They justified such actions on the grounds of losing control over life and that attacking others restored their feeling of power. At the most extreme point of self-destruction, suicide attempts were described as a last resort. The self is fractured, and the opportunity of feeling alive is denied, thus leaving the hopeless individual longing to heal his fractured self by death [33].

The interpersonal rejection experience brings about a mixture of negative and healthy states of mind that form reciprocity and tension. Eventually, there should be a balance between the pain and strength brought about from the rejection phase, which is critical in longterm coping [31].

An integrated model for the different coping methods and their effect is proposed. As can be seen, there is a mutual relationship between each part of the model, and no way of coping ensures permanent stability of the self.

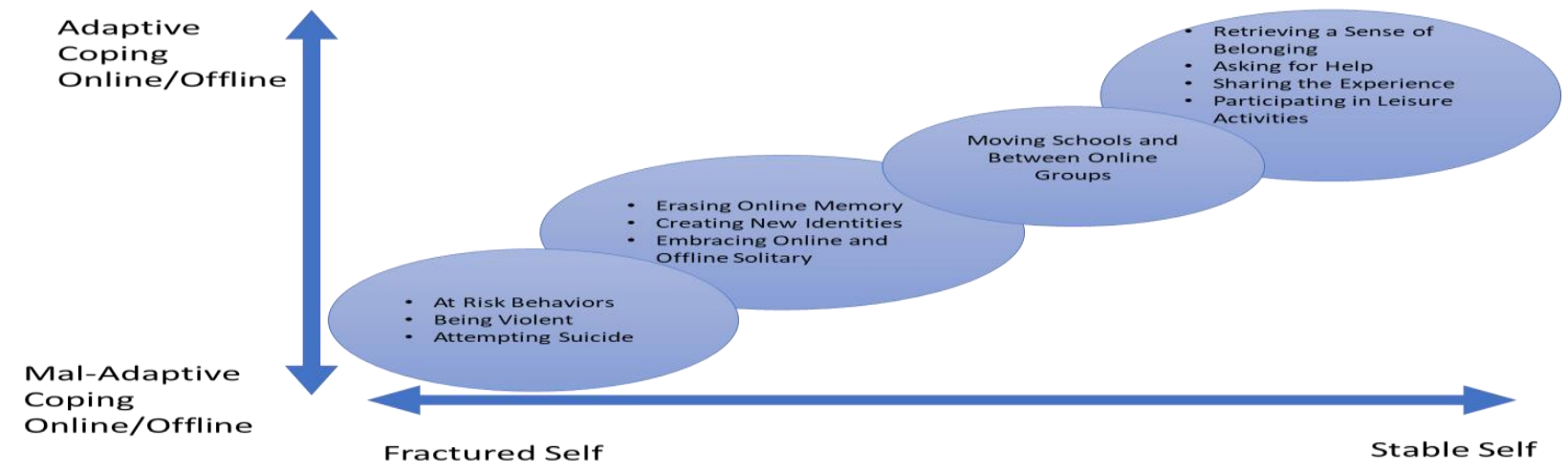

Figure 1: Integrated model of the different strategies of coping with interpersonal rejection ${ }^{1}$

\footnotetext{
${ }^{1}$ The axis Labels are from the literature: Adaptive/Maladaptive coping strategies were developed from the Multi-motive model of interpersonal rejection [38]; and the labels Fractured/Stable self are from Wilson [46].
} 


\section{Conclusions}

The study of social media and virtual communities usually focuses on the size of these communities, and their affordances. Here we take a different and novel approach. The aim of this paper was to understand the subjective perspective of youth suffering from online interpersonal rejection and how they coped with their experience. Learning about the different ways young people apply the variety of coping methods at their disposal will contribute to understanding of phenomena from their point of view. Moreover, distinguishing between adaptive, withdrawal and maladaptive coping methods provides valuable insights regarding the participants' various justifications and views on coping with life in general during the complex period of adolescence.

The research on online rejection is challenging; recruiting youth and maintaining ethical standards was difficult due to the age of the interviewees and the sensitivity of the topic studied.

This paper is part of a more extensive study, which used a mixed methods approach of qualitative methods and social network analysis. We believe that to enrich our knowledge regarding the experience of rejection various methodologies should be employed. Therefore, collecting data from online networks and analyzing it to explore social interactions is essential for further exploring the phenomenon under study.

\section{References}

[1] Asher, S.R., and J.D. Coie, Peer rejection in childhood, CUP Archive, 1990

[2] E. Babbie, The practice of social research, Thomson/Wadsworth Learning, Belmont, CA, 2004.

[3] R.F. Baumeister, and M.R. Leary, "The Need to Belong: Desire for Interpersonal Attachments as a Fundamental Human Motivation", Psychological Bulletin 117, 1995, pp. 497-529.

[4] N.N., Bazarova, and Y.H. Choi, "Self-disclosure in social media: Extending the functional approach to disclosure motivations and characteristics on social network sites", Journal of Communication 64, 2014, pp. 635-657.

[5] G. Becker, Disru pted lives how people create meaning in a chaotic world, University of California Press, Berkeley, CA, 1999.

[6] d. boyd, It's Complicated: The Social Lives of Networked Teens, Yale University Press, 2014.

[7] V. Braun, and V. Clarke, "Using thematic analysis in psychology", Qualitative Research in Psychology 3(2), 2006, pp. 77-101.

[8] E.S. Buhs, G.W. Ladd, and S.L. Herald, "Peer exclusion and victimization: Processes that mediate the relation between peer group rejection and children's classroom engagement and achievement?", Journal of educational psychology 98(1), 2006, pp. 1-13.
[9] N. Denzin, On Understanding Emotion., Jossey-Bass, San Francisco, CA, 1984.

[10] N. Elias, and D. Lemish, "Spinning the web of identity: The roles of the Internet in immigrant adolescents' search of identity", New Media \& Society 11, 2009, pp. 533-551. [11] M. Englander, "The interview: Data collection in descriptive phenomenological human scientific research", Journal of Phenomenological Psychology 43, 2012, pp. 1335.

[12] L. Floridi, The fourth revolution: How the infosphere is reshaping human reality, Oxford University Press, New York, 2014.

[13] W.L. Gardner, S. Gabriel, and A. Diekman, "The psychophysiology of interpersonal processes", In J. T. Cacioppo, L. G. Tassinary, and G.G. Bertson, ed., The Handbook of Psychophysiology. Cambridge University Press, Cambridge, MA, 2000, pp. 643-664.

[14] A. Giorgi, "The Descriptive Phenomenological Psychological Method", Journal of Phenomenological Psychology 43, 2012, pp. 3-12.

[15] T.E. Joiner, and C. Silva, "Why people die by suicide: further development and tests of the interpersonalpsychological theory of suicidal behavior.", In Meaning, mortality, and choice: the social psychology of existential concerns. American Psychological Association, Washington, DC, USA, 2012, pp. 325-336.

[16] R. Katz, and Y. Lavee, "Families in Israel", Handbook of world families, 2005, pp. 486-506.

[17] S. Kvale, Interviews: An introduction to qualitative research interviewing, Sage, Thousand Oaks, CA, 1996. [18] M.R. Leary, "Toward a conceptualization of interpersonal rejection”, In M. R. Leary, ed., Interpersonal rejection. Oxford University Press, New York, 2001, pp. 320.

[19] M.R. Leary, "Motivational and Emotional Aspects of the Self", Annual Review of Psychology 58(1), 2007, pp. 317-344.

[20] M.R. Leary, E. Koch, and N. Hechenbleikner, "Emotional responses to interpersonal rejection", In M.R. Leary, ed., Interpersonal Rejection. 2001, 145-166.

[21] Y.S. Lincoln, and E.G. Guba, Naturalistic inquiry, Sage, Beverly Hills, 1985.

[22] S. Livingstone, G. Mascheroni, and E. Staksrud, "European research on children's internet use: Assessing the past and anticipating the future", New Media \& Society 20(3), 2018, pp. 1103-1122.

[23] S. Livingstone, and J. Sefton-Green, The class: Living and learning in the digital age, NYU Press, New York, 2016. [24] M. L. Ranney, S.K. Pittman, A. Riese, M. Ybarra, J. Huang, A. Spirito, and R. Rosen, "Mobile Health Intervention Development Principles: Lessons from an Adolescent Cyberbullying Intervention", Proceedings of the 51th Hawaii International Conference on System Sciences, 2018, pp. 3329-3338.

[25] B. Major, and C.P. Eccleston, "Stigma and Social Exclusion”, In D. Abrams, M. A. Hogg and J. Marques, eds., The social psychology of inclusion and exclusion. Psychology Press, New York, NY, US, 2005, 63-87. [26] J.A. Maxwell, Qualitative research design: An interactive approach, Sage, Thousand Oaks, CA, 2005. 
[27] K.Y.A. McKenna, and J.A. Bargh, "Plan 9 from cyberspace: The implications of the Internet for personality and social psychology", Personality and Social Psychology Review 4, 2000, pp. 57-75.

[28] G.S. Mesch, G. Fishman, and Z. Eisikovits, "Attitudes Supporting Violence and Aggressive Behavior among Adolescents in Israel: The Role of Family and Peers", Journal of Interpersonal Violence 18(10), 2003, pp. 11321148.

[29] A.Y. Mikami, M.A. Boucher, and K. Humphreys, "Prevention of Peer Rejection Through a Classroom-Level Intervention in Middle School", The Journal of Primary Prevention 26(1), 2005, pp. 5-23.

[30] M.S. North, and Fiske, S.T., "Driven to exclude: how core social motives explain social exclusion", In N. DeWall, ed., Handbook of social exclusion. Oxford University Press, Oxford, England, 2013, 21-30.

[31] D. Oyserman, K. Elmore, and G. Smith, "Self, selfconcept, and identity", In M.L.\& J. Tangney, ed., Handbook of self and identity. Guilford, New York, 2012, 69-104. [32] M.Q. Patton, Qualitative evaluation and research method, Sage, Newbury park, CA, 1990.

[33] M. Pompili, "Exploring the phenomenology of suicide", Suicide and Life-Threatening Behavior 40(3), 2010, pp. 234 244.

[34] L. Rainie, and B. Wellman, Networked: The new social operating system, Mit Press, Cambridge, MA, 2012.

[35] C. Sedikides, "Self-protection", In M.R.L.and J.P. Tangney, ed., Handbook of self and identity. Guilford Press, New York, 2012, pp. 327-353.

[36] C. Sibona, "Unfriending on Facebook: Context Collapse and Unfriending Behaviors", Proceedings of the 47th Hawaii International Conference on System Sciences, 2014, pp. 1676-1685.

[37] L. Skitka, and E. Sargis, "Social psychological research and the Internet: the promise and peril of a new methodological frontier", In Y Amichai-Hamburger, ed., Social Net: The Social Psychology of the Internet. Cambridge Univ. Press, New York, 2005, pp. 1-25.

[38] L. Smart Richman, and M.R. Leary, "Reactions to Discrimination, Stigmatization, Ostracism, and Other Forms of Interpersonal Rejection", Psychological review 116(2), 2009, pp. 365-383.

[39] J. Smith, P. Flowers, and M. Larkin, Interpretative Phoneomological Analysis: theory, method and research, London: SAGE Publications, 2009.

[40] E. Staksrud, Ólafsson, K, and Livingstone, S., "Does the use of social networking sites increase children's risk of harm?", Computers in Human Behavior 29, 2013, pp. 40-50. [41] N. Tahmasbi, and E. Rastegari, "A Socio-contextual Approach in Automated Detection of Cyberbullying", Proceedings of the 51th Hawaii International Conference on System Sciences, 2018, pp. 2151-2160.

[42] E.D. Wesselmann, and K.D. Williams, "Ostracism and stages of coping”, In N. DeWall, ed., Handbook of social exclusion. Oxford University Press, Oxford, England, 2013, pp. 21-30.

[43] K.D. Williams, “Ostracism”, Annual review of psychology 58, 2007, pp. 425-452.
[44] K.D. Williams, “Ostracism: A Temporal Need-Threat Model”, In M. Zanna, ed., Advances in Experimental Social Psychology. Elsevier, 2009, pp. 275-314.

[45] K.D. Williams, and C.L. Govan, "Reacting to ostracism: Retaliation or reconciliation", In D. Abrams, M. A. Hogg and J. M. Marques, eds., The social psychology of inclusion and exclusion. Psychology Press, New York, 2005, pp. 47-62. [46] J.P. Wilson, “The posttraumatic self", In J.P. Wilson, ed., The posttraumatic self: Restoring meaning and wholeness to personality. Routledge, New York, 2006, pp. 399-424. 